\title{
INFORMAÇÃO EM REDE E O DIREITO À INFORMAÇÃO
}

\author{
Juliana Fachin \\ julianafachin@gmail.com \\ UFSC - Universidade Federal de Santa Catarina \\ Nelma Camelo Araújo \\ nelmacamelo@gmail.com \\ UFAL - Universidade Federal de Alagoas \\ Ursula Blattmann \\ ublattmann@gmail.com \\ UFSC - Universidade Federal de Santa Catarina
}

Resumo: Essa reflexão apresenta a questão do direito à informação nas redes sociais, com base em autores interdisciplinares, nas áreas de sociologia, comunicação, administração e informação. Aponta a esfera pública e suas ações, bem como a representatividade social e o acesso à informação disponível nas redes sociais. Tece considerações sobre o direito de opinião pública na mobilização no sentido de caminhos alternativos para o acesso a informação. A discussão permeia a ação governamental, as reivindicações sociais no que diz respeito ao acesso informacional e a influência do mercado nas tomadas de decisões por parte das ações públicas governamentais.

Palavras-Chave: Esfera pública; representatividade social; redes sociais

\section{Information network and the right to information}

Abstract: This reflection presents the question of the right to information on social networks, based on interdisciplinary authors in the fields of sociology, communication, administration and information. Points the public sphere and their actions, as well as social representation and access to information available on social networks. Reflects on the right to public opinion in the mobilization for alternative ways to access the information. The discussion permeates government action, the social demands with regard to the informational access and market influence in decision made by government public actions. Keywords: Public sphere; social representation; social networking.

\section{Red de información y el derecho a la información}

Resumen: Esta reflexión presenta la cuestión del derecho a la información en las redes sociales, basado en autores interdisciplinarios en los campos de la sociología, la comunicación, la administración y la información. Los puntos de la esfera pública y sus acciones, así como la representación social y el acceso a la información disponible en las redes sociales. Se reflexiona sobre el derecho a la opinión pública en la movilización de formas alternativas para acceder a la información. La discusión involucra la acción del gobierno, las demandas sociales respecto al acceso de información y la influencia del mercado en la toma de decisiones mediante acciones públicas del gobierno.

Palabras clave: Esfera pública; representación social; información en redes sociales. 


\section{Introdução}

O interesse em saber o que está acontecendo no mundo não é privilégio da sociedade do século XXI conectada nas redes, o homem tem e sempre teve a necessidade de registrar as coisas, de transmitir o seu conhecimento, de forma com que todos possam saber e participar.

Devido a esse interesse inerente do homem e a descoberta de que, informação é poder, o século da sociedade do conhecimento desencadeou a incessante procura por informação, governos, sociedade, organizações, mercado financeiro etc.

Nesta necessidade em saber tudo, vários países buscam descobrir o que os outros países estão fazendo, pensando ou buscando. Castells (2015) aborda sobre o tema, indicando que os maiores espiões do momento são: Estados Unidos da América e Alemanha, todos os outros países participam com seus próprios sistemas de espionagem, um vigia o outro e com isso se tem a cultura do saber tudo de todos, é de interesse inerente dos que estão no poder, sempre foi.

O direito de acesso à informação é matéria recorrente em todo o mundo, a preocupação que organizações como a Wikileaks têm em disponibilizar documentos secretos, informações governamentais, para o acesso de todos, cita o caso do ativismo social, feito por pessoas como Edward Snowden, da organização social articuladas para que esse tipo de ação aconteça, cada vez mais frequente em vários lugares do mundo.

Segundo Castells (2015) a Espanha cedeu aos EUA o direito de vigiar as informações de seus cidadãos por três anos, em troca de um equipamento de espionagem mais sofisticado.

A informação tornou-se mercadoria de troca, venda e roubo. A sociedade não tem mais privacidade (CLAVELL, 2015), suas informações mais pessoais estão interligadas nas redes sociais. No quadro 1 Tecnologias e dispositivos que produzem ou armazenam dados das atividades diárias de Clavell, aponta claramente a vigilância existente e como participamos sem consciência dessa realidade:

Quadro 1 Tecnologias e dispositivos que produzem ou armazenam dados das atividades diárias

\begin{tabular}{|c|c|}
\hline Tecnologias & Vigilância das atividades \\
\hline Videovigilância & As imagens podem ser interceptadas. \\
\hline $\begin{array}{l}\text { Medidores de eletricidade } \mathrm{e} \\
\text { termostatos }\end{array}$ & Possibilitam fornecem informação sobre hábitos. \\
\hline $\begin{array}{l}\text { Televisores inteligentes } \mathrm{e} \\
\text { consoles de videogames }\end{array}$ & $\begin{array}{l}\text { Possuem câmeras e microfones (imagem e som) par } \\
\text { reconhecimento facial e sonoro }\end{array}$ \\
\hline $\begin{array}{l}\text { Controles biométricos de entrada } \\
\text { e saída }\end{array}$ & $\begin{array}{l}\text { Controle dos horários em que a pessoa comparece e se } \\
\text { ausenta }\end{array}$ \\
\hline $\begin{array}{l}\text { Monitoramento remoto no } \\
\text { trabalho }\end{array}$ & $\begin{array}{l}\begin{array}{l}\text { Capturas de tela para medir a produtividade do } \\
\text { trabalhador }\end{array} \\
\end{array}$ \\
\hline Bases de dados pessoais & Podem conter dados fiscais e de saúde dos clientes \\
\hline
\end{tabular}




\begin{tabular}{|l|l|}
\hline $\begin{array}{l}\text { Sensores de contagem de } \\
\text { pessoas }\end{array}$ & $\begin{array}{l}\text { Monitoram o fluxo de compradores e os tempos de } \\
\text { compra }\end{array}$ \\
\hline Cartões de fidelidade & Em troca de descontos, criam perfis do comprador \\
\hline Ibeacons & Enviam ofertas para celulares próximos \\
\hline Wifi gratuito & $\begin{array}{l}\text { Pode ser oferecido em troca do acesso ao perfil do } \\
\text { Facebook }\end{array}$ \\
\hline Bilhetes de transportes públicos & $\begin{array}{l}\text { Cartões recarregáveis que produzem dados de } \\
\text { deslocamentos }\end{array}$ \\
\hline Redes de bicicletas pública & Registro dos trajetos \\
\hline Carros & $\begin{array}{l}\text { Existem sistemas para ler as placas (em estacionamentos, } \\
\text { garagens) }\end{array}$ \\
\hline Telefonia móvel & Permite geolocalizar pessoas \\
\hline $\begin{array}{l}\text { Câmeras térmicas e sensores } \\
\text { sonoros }\end{array}$ & Medem o fluxo de pedestres e níveis de ruído \\
\hline Mobiliário urbano & Detecta a presença de pedestres \\
\hline Sistemas de estacionamento & $\begin{array}{l}\text { O pagamento com cartão de vagas azuis e verdes gera } \\
\text { dados do usuário }\end{array}$ \\
\hline
\end{tabular}

Fonte: Adaptação de Clavell (2015)

Ao utilizar o Facebook (em fevereiro de 2015 mais de noventa milhões de usuários no Brasil), Twitter, YouTube, blogs para acessar, publicar, isto é, disponibilizar conteúdos: fotografias, vídeos, opiniões, texto e dados pessoais, o indivíduo torna disponível e acessível seus dados pessoais na moeda da troca - escambo no sentido de poder acessar o ambiente e localizar pessoas de suas relações profissionais ou pessoais. Os Governos e as diferentes Organizações cadastram diferentes tipos de dados em suas bases de dados, como exemplo, o imposto de renda, conta bancária, registros pessoais (RG, CPF, título de eleitor, endereço, entre outros).

Tornando-se público o particular e colocando em risco a sua privacidade e sua segurança pessoal, o maior exemplo desses recursos é um banco de dados biográfico que tornou-se um meio de exclusão social quem não o preencher (é a plataforma Lattes, que contém a informação para aqueles que preenchem o formulário: Declaração: O solicitante declara formalmente que está de acordo com o Termo de adesão e compromisso da Plataforma Lattes (declaração feita em observância aos artigos 297-299 do Código Penal Brasileiro) no sentido de quando a pessoa não preenche está automaticamente excluída de processos de seleção em universidades, programas de pós-graduação, editais e assim por diante.

A preocupação não é omitir as informações, mas sim, saber onde elas estão, quem coordena e tem acesso, o que irão fazer com todos esses dados e informação?

Mediante estas colocações, o texto visa desencadear reflexões a respeito da informação em rede sociais, seu acesso e o papel da esfera pública neste cenário informacional, afim de explanar pontos inerentes para a discussão, usando como base os autores: Castells (2015) e 
Aubin (2015), Scherer-Warren (2011), Santos (2004), Habermans (2003), Bauman (2001), Morin (2000), Carvalho (2000).

\section{A esfera pública e a informação em rede}

A existência de movimentos sociais articulados demonstra que a democracia, de alguma forma tende a funcionar, pois a sociedade, de um jeito ou de outro, consegue se articular, apesar de que, em uma democracia a busca por um consenso nunca terminará, pois, é impossível agradar a todos. Mesmo assim, Habermas (2003) recomenda que, a construção de uma sociedade deve ser feita por meio da democracia.

Aubin (2015) expõem o exemplo das ações de Porto Alegre com o programa denominado de "orçamento participativo", em que, os cidadãos tomam decisões em todos os níveis, um exemplo para outros países, como uma forma de participação social, base sobre o que conhecemos de democracia.

A sim como há uma forte influência do mercado em convergência com a atuação do governo, inclusive na constituição de leis, também existem movimentos que fazem preção, fazendo com que, em certos momentos trabalhe para a sociedade em outros para o mercado, em casos específicos ele atua para os dois, e em outros, ele não atende há nenhum, depende dos interesses por trás de cada ação.

Habermans (2003) expõe sobre a representatividade pública, como algo subjetivo, cheio de preceitos e dogmas, representando algo ou alguém, e isso se faz, de alguma forma, na esfera pública.

Aspectos da produção da informação, voltada para o comércio da informação, quem informa quem? Quem dá as concessões de uso e exploração de redes de comunicação? Quem se beneficia com isso? Aubin (2015) indica o caso Canadense, em que, as informações não são deliberadas livremente, nem todos podem dizer o que pensam ou sabem, e a ação da esfera pública, fica entre meio a todos os interessados, vigiando, ao mesmo tempo que concede o acesso à alguns interesses do público.

O uso de diversos tipos de serviços está disponível em meio digital, a gama de usuários é vasta, vai desde crianças à idosos, em muitos países o governo não oprime o acesso, apenas vigia, obtém informações, e, se for o caso toma providências.

No caso do uso de informações, o papel dos intelectuais na esfera pública e estratégia organizacionais, podem servir para ambos os lados, governamental ou social. Essas pessoas detêm de muito conhecimento, como o caso mencionado de Edward Snowden, servia aos interesses do governo, por algum motivo, resolveu disponibilizar para a sociedade diversos 
documentos contendo ações secretas de países poderosos como os "EUA", entre vários outros casos, disponíveis na página Wikileaks.

Conforme Castells (2015), o governo não tem como controlar a internet, mas, tem como vigiar, espionar e antecipar ações, porém, ele também usa as redes para realizar suas funções, por isso, igualmente está suscetível aos ataques de hacker/cracker.

Concordamos com o fato de que sempre haverá a "esquerda e a direita", uma forma racional de democracia, equilibrando ambos os lados, os que guardam, e os que disponibilizam a informação.

\section{Direito à informação}

O direito à informação igualmente adentra no caso dos direitos autorais, com dois lados: um, está o direito de acesso à informação, e o outro, o direito de produzir e lucrar com o produto intelectual, em ambos, a lei de direitos impacta sob a ótica de quem tem o direito? $\mathrm{E}$ como fazer com que, pessoas ganhem financeiramente com a produção de uma obra ao mesmo tempo em que, a sociedade possa ter acesso a essa informação produzida, clássica discussão da produção científica, a resposta ou solução, ainda não foi encontrada, pois há dois aspectos de tamanho e impacto iguais, o que produz e o que gostaria de ter acesso, de que forma amenizar à essa necessidade informacional com as questões econômicas, e quem pode fazer isso?

Devida à está questão, muitos movimentos nas redes, fórum: The Pirate Bay, mobilizamse para disponibilizar, gratuitamente, materiais restritos sob a lei de direitos autorais, como o caso dos materiais áudio visuais: músicas, filmes, livros e qualquer outro material que acharem conveniente, os quais as leis não permitiriam, esses grupos visam atender aos interesses da sociedade, quanto o direito de acesso à informação desses materiais. ${ }^{1}$

Carvalho (2000, p. 119) relata a importância da informação "como elemento essencial para a sobrevivência humana e o computador o principal vetor das transformações sociais", o relato está fundamentado na publicação de Daniel Bell, livro publicado pelo autor em 1960. Diante dessa premissa podemos observar que as ferramentas de uso, acesso e disseminação da informação tem evoluído de forma a possibilitar ao "humano" interagir de formas variadas entre a informação e a máquina (computador).

No Brasil existe uma peculiaridade, devida a lei n. 9610 de 1998 de direitos autorais, vigora a possibilidade do autor intelectual de "ceder" seus diretos a uma produtora, editora e

\footnotetext{
1 Veja mais sobre o assunto em: SILVA, Ana Magalhães. Os capitães da pirataria. Revista Trip. 16 mar. 2009. Disponível em: <http://revistatrip.uol.com.br/revista/175/especial/os-capitaes-da-pirataria.html>. Acesso em: 24 jun. 2015.
} 
ou agentes que comercializem sua produção, permitindo a esses representantes lucrarem com sua ideia. Diante disso, cria-se uma imagem, de que, quem lucra é o autor, e ele cerceia o acesso direto a sua produção, mas, seus representantes se manifestam em juízo para reivindicar qualquer acesso por parte da sociedade, para que não sejam gratuitos, pois existem interesses comerciais por trás dos direitos autorais.

A mesma coisa acontece com o direito de expressão, em muitos países, pensadores, estudiosos, cientistas entre outros, não podem expressar o que pensam publicamente, há uma forte pressão e discussão sobre o direito de poder falar e se expressar publicamente, falar sobre assuntos que envolvem a ação governamental é perigoso, para entender melhor o assunto, Aubin (2015) indica a leitura do livro: Os últimos intelectuais de Russell Jacoby (1990).

A grande questão que envolve a opinião dos cientistas ao se tornar "pública" está relacionada com o posicionamento do governo perante as indagações científicas de pesquisas sobre meio ambiente e a influência do mercado com relação a este meio. Entender os acordos comerciais são difíceis, pois as cláusulas contratuais não deixam claro quem se beneficia com o uso dos produtos extraídos do meio ambiente, nem quem são os responsáveis por possíveis danos, nesse sentido, a opinião científica é abafada e secretada nas ações do governo com o mercado.

Aubin (2015) menciona que as pesquisas realizadas, e que estão diretamente relacionadas aos interesses do governo, como a extração de petróleo e suas consequências, não são permitidas a divulgação, seja por parte da instituição que está realizando a pesquisa ou pela equipe de pesquisadores, há censura e medo em torno do assunto, essas pesquisas são feitas na "clandestinidade" por tratar-se de assuntos delicados, dependendo do país em discussão.

Essa informação foi confirmada por Castells (2015), o sociólogo expos que diferente do Brasil, os órgãos de governo Espanhol não disponibilizam, publicamente, informações sobre pesquisas que envolvam financiamento governamental.

No Brasil o artigo 5o da Constituição Federal (1988) garante direito à informação. Considerando que o direito é negado para a grande maioria das pessoas pelos órgãos oficiais e assim criou-se uma nova lei "de acesso a informação" em 2011 para viabilizar o direito de acesso a informação, mas o que se percebe não bastam as leis e sim ações concretas em disponibilizar a informação nas diversas instâncias. As instâncias se refugiam nas leis e no "balcão de informação" de órgãos públicos (na biblioteca, em hospitais e delegacias) coloca-se o artigo sobre o desacato (BRASIL, Código Penal - Art. 331: Desacatar funcionário público no exercício da função ou em razão dela). Sendo que é fundamental "prestar a informação" a qualquer cidadão. 


\section{Representatividade social}

A necessidade em ter acesso às informações, e saber o que acontece, faz com que a sociedade civil tem utilizado as redes sociais para denunciar, questionar ou se mobilizar contra ações que consideram favoráveis ou desfavoráveis. Isso tem causado impactos na autoria, na propriedade, e no ciclo do fluxo da informação (do emissor ao receptor). Conforme Bellei (2002) o autor é o leitor e o leitor transforma-se em autor, e surge o "lautor". Enquanto Alvin Tofler (1986) menciona o produtor consumidor o qual gera o prosumer.

As redes sociais viabilizam que determinada mensagem torna-se notícia global de forma muito rápida, sem preservar barreiras territoriais e exponencializa-se pelo curtir ou twittar. Assim vemos a obra de Pierre Levy (1996), "o que é o virtual?", somada pelo comunicador Mc Luhan (em sua obra "Galáxia de Gutenberg", sobre as mutações na educação.

Para Morin (2000, p. 22) o uso das redes sociais se tornou uma ferramenta viável para a sociedade se conectar, se articular e se mobilizar como forma de desenvolvimento social. "Somos, por tanto, produtos e produtores no processo da vida. Da mesma maneira, somos produtores da sociedade porque sem indivíduos humanos não existiria a sociedade [...]"

A primavera Árabe, mobilização social em um ambiente que o governo é autoritário, esses tipos de manifestações surtem repercussões, pois nem sempre são analisadas adequadamente as causas e as consequências sejam da sociedade ou dos detentores do poder. Para Santos (2004), o fator que acarretará em várias mudanças acontecerá quando, as pessoas aprenderem a valorizar em primeiro lugar o indivíduo, a partir daí a civilização se tornará um lugar melhor, consequentemente as pessoas também.

Aubin (2015) exemplifica a situação em Quebec, o governo não se dobra à esse tipo de manifestações, ao contrário, investiga, espiona e reprime os grupos de liderança, assim como o caso dos 50 mil estudantes que foram às ruas para manifestar-se contra a austeridade do governo, no que se refere aos cortes de verbas nas áreas da: educação, saúde e ações envolvendo o meio ambiente, ao invés de ouvir os questionamentos do povo o governo reprimir suas opiniões, cria leis que vigiam e monitoram os movimentos sociais reivindicadores, obrigando esses movimentos a usarem outros meios comunicativos, mudando de estratégia para que possam mobilizar-se contra as ações do governo.

Percebe-se que esse tipo de repressão, de ordem social, ocorre principalmente nos países mais desenvolvidos, sendo usado principalmente os instrumentos e aparelhos da esfera pública. Nos países em desenvolvimento, como o caso brasileiro, os mecanismos de repressão por parte da sociedade não ocorrem tão ostensivamente, por que a própria população desconhece as fontes de informação que podem utilizar em seu próprio benefício, e essas fontes mantém informações desatualizadas, desencontradas e ou não acessíveis. 
Scherer-Warren (2011) menciona o impacto do empoderamento social como reflexo das ações mobilizatórias em diversos segmentos, principalmente da cultura indenitária desses grupos em se articular através das redes sociais.

O uso dessas redes sociais vem de encontro com a necessidade de representatividade social, no que se refere à massa, sociedade desfavorecida e sem "voz", sem meios de se expressar, a sociedade quer ser ouvida, quer ser atendida, mas, não há como atender a todos, por isso as deliberações podem favorecer quem estiver no poder, de quem pode falar, por mais que existam órgãos como a ONU, é difícil proferir que esta parcela da sociedade seja representada opinativamente, é uma competição desleal, o poder contra a pretensão, quem tem maiores condições de vencer?

A mesma coisa acontece com os imigrantes, eles são povos, na maioria das vezes, indesejados, por seus costumes, religião e cultos, países poderosos fecham suas fronteiras para pessoas indesejadas, muitas vezes os abrigam em um campo de refugiados até que a situação de seu país os permitam voltar, mas, voltar para onde, para quem, como? Quando ficam, como aceitar a situação de um povo diferente com cultos diferentes, em uma situação, em que, não têm representatividade, mediação e informação, sua condição parece ser mais transitória, a resposta sempre vêm sob o discurso hegemônico de um consenso comum, de cada país. 0 Sociólogo Bauman (2001), realiza reflexões a respeito do assunto, relatando as tendências sociais derivadas do reflexo da globalização, assim como as mobilizações e o engajamento social nas ações políticas.

A exemplo desse contexto, temos hoje no Brasil a questão da imigração Haitiana, que chega pelo estado do Acre e é distribuída a várias regiões do Brasil, em muitas dessas regiões esses imigrantes, mesmo que tenham uma formação adequada, inclusive com conhecimento de duas ou mais línguas, a situação é discriminatória, pois, por sua condição de imigrantes, advindo de uma área "miserável" e por ser de uma raça que sofre preconceito ao longo de muitos séculos e em diversos países no mundo, essas pessoas são "armazenados" em condições desumanas, exercendo funções irrisórias.

Basta olharmos um pouco a história, não muito longe, especificamente na década de 1980, brasileiros migravam para os Estados Unidos, na esperança de alcançar oportunidades melhores que no Brasil, porém, quando lá chegavam se submetiam a trabalhos que os americanos não queriam, quando não eram deportados de volta ao Brasil em condições humildes.

Concordamos com Morin (2005, p. 357) ao mencionar que, "O desenvolvimento ignora aquilo que não é calculável nem mensurável, isto é, a vida, o sofrimento, a alegria, o amor", porém, para que o desenvolvimento não se sobreponha aos interesses sociais é preciso ter 
uma governança com ações igualitária, para que haja um equilíbrio, um meio termo entre o desenvolvimento e a condição humana.

Conforme Habermans (2003) a condição social vai sempre exigir ajustes seja do movimento político, econômico ou mesmo social, indo e vindo nas transições do que é certo ou errado, do que faz bem ou mau para o homem, e nesta busca o meio se constrói e se destrói, sempre na busca por um ideal.

Diante disso, as bibliotecas, museus e arquivos tem um papel fundamental, pois são instituições públicas que além de conterem acervos de diversos formatos, sobre diversas áreas, ou na sua especificidade no caso de arquivos e museus, permitem o acesso à informação ao público em geral, de forma gratuita.

Para finalizar a reflexão sobre o tema, consideramos que o profissional da informação deve nortear os campos destas reflexões, escolhendo os caminhos a seguir, o de orientar, propiciar o acesso, e até mesmo, promover reflexões sobre determinados assuntos, ações ou de servir ao tipo de esfera pública na sua organização burocrática, econômica que age de forma inibidora no desenvolvimento social, cultural e econômico de um país.

Nos Estados Unidos, as bibliotecas públicas têm função fundamental na orientação aos imigrantes sobre documentação, tradução de bula de remédios e outras orientações necessárias e que os imigrantes venham a procurar. Os museus no mundo são tratados com reverência, pois evidencia a trajetória da cultura de um povo, essas instituições são valorizadas nos países mais desenvolvidos, uma vez que nem todas as informações geradas pelo governo são disponibilizadas.

Diferente dos países em desenvolvimento, as informações produzidas pelas instituições públicas estão disponíveis, mesmo que em parte desatualizadas, porém as bibliotecas, arquivos e museus, são deixados a margem e sob condições deploráveis, sem recursos financeiros e humanos. Cabe a sociedade se articular, empoderando esses espaços públicos para que possam ganhar voz, serem vistos e ouvidos, ter oportunidade de decisão e efetiva representatividade no governo. Ou se pensa no ser coletivo ou seremos ilhas.

\section{Considerações finais}

Esta reflexão norteou-se com base na palestra dos professores: France Aubin e Manuel Castells. Ambos proporcionaram reflexões a respeito das esferas públicas, bem como a atuação da sociedade diante de algumas situações, como o caso de reivindicações, representatividade pública e uso de redes sociais para articulações sociais (para o bem coletivo). Essa perspectiva global envolve diversos direitos, inclusive o de acesso à informação, mas também os deveres, isto é, as responsabilidades sociais que o indivíduo tem perante a sociedade. 
Os profissionais da ciência da informação no Brasil precisam conhecer as mudanças do contexto social, identificar as demandas informacionais e acima de tudo ampliar possibilidades de oferta de fontes de informação no sentido de atender o direito à informação. O acesso à informação pública no mundo ocorre diferenciada, muitos países dispõe suas informações ao acesso público, privilegiando adotar uma política que possibilite ao público o acesso à informação, comunicação, cultura e educação qualitativas, por meios de suas instituições memoriais, como bibliotecas, museus e arquivos. As informações que envolvam pesquisas e de interesses governamentais são de acesso restrito, mas podem ser disponibilizadas em repositórios institucionais no intuito de manter a memória coletiva e ativar mecanismos de controle bibliográfico (seja impresso ou digital).

\section{Referencias}

AUBIN, France. Palestra sobre esferas públicas e o direito do público a informação. Programa de Pós-Graduação em Jornalismo PGJOR da Universidade Federal de Santa Catarina (UFSC), 2015. (Informação verbalizada). Disponível em: <http://ppgjor.posgrad.ufsc.br/2015/04/21/palestra-esferas-publicas-e-o-direito-do-publico-ainformacao-com-a-profa-dra-france-aubin-da-universite-du-quebectrois-rivieres-canada/> .

BAUMAN, Zygmunt. Globalização: as consequências humanas. Rio de Janeiro: Zahar Ed., 2001. BELLEI, Sérgio Luiz Prado. O livro, a literatura e o computador. Florianópolis: EDUFSC, 2002. BRASIL. Lei n. 2848 de 1940, Código Penal. Diário Oficial [da] República Federativa do Brasil, Brasília, DF, 31 dez. 1940.

BRASIL. Constituição Federal do Brasil. Diário Oficial [da] República Federativa do Brasil, Brasília, DF, 05 out. 1988.

BRASIL. Lei n. 9610 de 1998, de direitos autorais. Altera, atualiza e consolida a legislação sobre direitos autorais e dá outras providências. Diário Oficial [da] República Federativa do Brasil, Brasília, DF, 19 fev. 1998.

BRASIL. Lei n. 12527, de acesso a informação. Regula o acesso a informações previsto no inciso XXXIII do art. $5^{\circ}$, no inciso II do $\S 3^{\circ}$ do art. 37 e no $\S 2^{\circ}$ do art. 216 da Constituição Federal; altera a Lei $\mathrm{n}^{\circ}$ 8.112, de 11 de dezembro de 1990; revoga a Lei $\mathrm{n}^{\circ} 11.111$, de 5 de maio de 2005, e dispositivos da Lei $n^{\circ} 8.159$, de 8 de janeiro de 1991; e dá outras providências. Diário Oficial [da] República Federativa do Brasil, Brasília, DF, 18 nov. 2011. 
CARVALHO, Kátia de. Informação e Comunicação: novas fronteiras, novas estratégias. In: LUBISCO, Nídia M. L.; BRANDÃO, Lídia M. B. Informação \& Informática. Salvador: EDUFBA, 2000. p. 119-142. Disponível em: <

https://repositorio.ufba.br/ri/bitstream/ufba/129/3/Informacao\%20e\%20Informatica.pdf $>$. Acesso em: 04 jul. 2015.

CASTELLS, Manuel. Aula Magna: Os efeitos da informação em rede. Florianópolis: UDESC, 14 maio, 2015. (Informação verbalizada). Disponível em:

<http://www.udesc.br/?idNoticia=12925>. Acesso em: 20 jun. 2015.

CLAVELL, Gemma Galdon. A batalha pelos dados: o que acontece com nossos dados na Internet? El País, 11 jun. 2015. Disponível em: <

http://brasil.elpais.com/brasil/2015/06/12/tecnologia/1434103095_932305.html >. Acesso em: 04 jul. 2015.

CONSELHO Nacional de Desenvolvimento Científico e Tecnológico - CNPq. Curriculo Lattes. Termo de Adesão e de Condições de Uso Sistema de Currículos da Plataforma Lattes. Brasília: CNPq, s.d. Disponível em: < https://wwws.cnpq.br/cvlattesweb/pkg publicar.mostrar termo comp >. Acesso em: 04 jul. 2015.

CONSELHO Nacional de Desenvolvimento Científico e Tecnológico - CNPq. Currículo Lattes.

Disponível em: < http://lattes.cnpq.br/ >. Acesso em: 01 jul. 2015

HABERMAS, Jürgen. Mudança estrutural da Esfera Pública: investigações quanto a uma categoria da sociedade burguesa. Rio de Janeiro: Tempo Brasileiro, 2003. 398p.

JACOBY, Russell. Os últimos intelectuais: a cultura americana na era da academia. Trad. Magda Lopes. São Paulo: Trajetória Cultural: Edusp, 1990.

JORNAIS brasileiros resistem ao Facebook. Meio \& Mensagem, 07 jul. 2015. Disponível em: < http://www.meioemensagem.com.br/home/midia/noticias/2015/07/06/Jornais-brasileirosresistem-ao-Facebook.html>. Acesso em: 07 jul. 2015.

LEVY, Pierre. O que é virtual? São Paulo: Editora 34, 1996. (Coleção Trans).

MCLUHAN, Marshall. A galáxia de Gutenberg: a formação do homem tipográfico. São Paulo: Ed. Nacional: Ed. da Universidade de São Paulo, 1972. 90p. (Cultura, sociedade, educação). 
MORIN, Edgar. Uma mundialização plural. In: MORAES, Denis de (Org.). Por uma outra comunicação: mídia, mundialização cultural e poder. Niterói: Record, 2005.

MORIN, Edgar. Da necessidade de um pensamento complexo. In: MARTINS, Francisco Menezes; SILVA, Juremir Machado da (Orgs.). Para navegar no século XXI: tecnologias do imaginário e cibercultura. 2. ed. Porto Alegre: EDIPUCRS, 2000.

POMERANTZ, David. Greenpeace: Protesto contra a NSA. Greenpeaceblogs.org, 27 jun. 2014. Disponível em: <http://greenpeaceblogs.org/2014/06/27/greenpeace-takes-skies-protest-nsasillegal-internet-spying/>. Acesso em: 05 jun. 2015.

SANTOS, Milton. Por uma globalização. 11 ed. Rio de Janeiro: Record, 2004.

SCHERER-WARREN, Ilse; LÜCHMANN, Lígia Helena Hahn (Orgs.). Movimentos sociais e participação: abordagens e experiências no Brasil e na América Latina. Florianópolis: Editora UFSC, 2011.

THEPIRATEBAY. Homepage. 2015. Disponível em: <https://thepiratebay.mn/>. Acesso em: 18 jun. 2015.

TOFFLER, Alvin, 1928-. A terceira onda. 13. ed. Rio de Janeiro: Record, [1986?] 491p.

WIKILEAKS. Sobre o Wikileaks. 2015. Disponível em: <https://wikileaks.org/About.html>. Acesso em: 05 jun. 2015.

Recebido/Recibido/Received: 2015-06-11. Aceitado/Aceptado/Accepted: 2015-07-31. 